\title{
Multicentric ameboma of the colon mimicking Crohn's disease
}

\author{
Biggs Saravanan Ramachandran, Bright Thomas ${ }^{1}$, Shana Baby, Rosamma Thomas ${ }^{2}$ \\ Departments of Gastroenterology and ${ }^{1}$ Radiology, Bharath Hospital, Kottayam, ${ }^{2}$ Department of Pathology, Sree Narayana Medical College, \\ Ernakulum, Kerala, India
}

\begin{abstract}
\end{abstract}
\section{Introduction}

Amoebiasis is one of the most frequent parasitosis worldwide, but its incidence is higher in developing countries. Ameboma is a complication caused by Entamoeba histolytica invasion of the intestinal wall occurring approximately in $1.5 \%$ of cases. The present case highlights the importance of considering a differential diagnosis of ameboma, when the gross appearance of the lesion resembles Crohn's disease or multicentric neoplasm.

\section{Address for correspondence:}

Dr. Biggs Saravanan Ramachandran, Department of Gastroenterology, Bharath Hospital, Kottayam, Kerala, India. E-mail: rbiggs21@yahoo.com

\begin{tabular}{|l|c|}
\hline \multicolumn{2}{|c|}{ Access this article online } \\
\hline \multirow{2}{*}{ Website: } & Quick Response Code \\
\hline www.jdeonline.in & \\
\hline DOI: & \\
10.4103/0976-5042.159245 & \\
\hline
\end{tabular}

\section{Case Report}

A 64-year-old diabetic lady came with 4 months history of abdominal pain over the right side and weight loss. She also had loss of appetite, vomiting, tenesmus, and infrequent bowel movements. There was no history of fever, diarrhea or bleeding per rectum. She didn't give a history of nonsteroidal anti-inflammatory drugs intake or corticosteroid use. On physical examination, she was found to have pallor, tenderness in right side of the abdomen, and a right iliac fossa mass. There was no hepatosplenomegaly. Blood investigations were within normal limits. Contrast-enhanced tomographic scanning (computed tomography [CT]) of abdomen depicted

This is an open access article distributed under the terms of the Creative Commons Attribution-NonCommercial-ShareAlike 3.0 License, which allows others to remix, tweak, and build upon the work non-commercially, as long as the author is credited and the new creations are licensed under the identical terms.

For reprints contact: reprints@medknow.com

How to cite this article: Ramachandran BS, Thomas B, Baby S, Thomas R. Multicentric ameboma of the colon mimicking Crohn's disease. J Dig Endosc 2015;6:76-8. 
an irregular inhomogenously enhancing mass involving cecum (measuring $24 \mathrm{~mm} \times 25 \mathrm{~mm}$ ) and a circumferential, irregular and nodular inhomogenously enhancing mass in the hepatic flexure of colon measuring approximately $3.5 \mathrm{~cm}$ in length and $1.5 \mathrm{~cm}$ in thickness. There were short segmental and circumferential wall thickening of splenic flexure of colon (4 $\mathrm{cm}$ in length and $8 \mathrm{~mm}$ in thickness) and proximal part of transverse colon, suggestive of a multicentric growth or Crohn's disease [Figure 1]. The patient was taken up for colonoscopy which revealed multiple, circumferential, ulcerated, friable, stricturizing lesions with intervening normal mucosa, involving cecum, proximal ascending colon, splenic flexure of colon, and proximal part of transverse colon. There were multiple aphthous ulcers and linear serpentine ulcers in the proximal rectum. Terminal ileum and ileocecal valve appeared normal [Figure 2]. After colonoscopy, initial differential diagnoses of Crohn's disease and multicentric colonic growth were made. Histopathological examination revealed focal necrosis, extensive ulcerated lesions with covering granulation tissue, and few trophozoites of E. histolytica with ingested red blood cells inside [Figure 3]. Hence, the final diagnosis of ameboma presenting as multicentric mass was made. The patient was treated with oral nitroimidazole derivatives ornidazole for 1-week. She became better in a week time. During follow-up, she was taken again for colonoscopy which showed complete resolution of the lesions in all the locations. The CT scan which was done 4 weeks after the treatment showed no residual lesions.

\section{Discussion}

Amoebiasis is the most significant gastrointestinal parasitic infection in developing countries like India. Infections caused by E. histolytica are the second most common type of parasitosis in the world (Malaria being the first), accounting for 40,000-100,000 deaths annually. ${ }^{[1]}$ Ninety percentage of the population remains asymptomatic and live a normal life and only $6-11 \%$ of the patients show symptomatic amoebic infection. ${ }^{[2]}$

Intestinal E. histolytica infection can lead to asymptomatic carrier state, colitis, and abscess formation to colonic perforation. Trophozoites of E. histolytica are responsible for the invasive disease. Rarely, patients with long-standing partially or untreated infection develop tumorous, exophytic, cicatricial, and inflammatory masses known as "amebomas" or "amebic granulomas". ${ }^{[3]}$ It has been estimated that of all the cases with amebiasis, ameboma formation occurs in about $1.5 \%$ of the patients. ${ }^{[4,5]}$ Colonic amebomas have become rare even in endemic areas because of the availability of effective therapy. ${ }^{[6]}$ Complications resulting from intestinal amoebiasis seem to be more common in diabetics. Among those suffered amebic colitis with complications, $40 \%$ were reported to be diabetic patients. ${ }^{[7]}$ Amebomas are usually solitary and variable in size, but they can be multiple. ${ }^{[6,8]}$ Men within the second and fifth decades of life are most commonly affected. ${ }^{[6,8]}$ It occurs in adults after an attack of
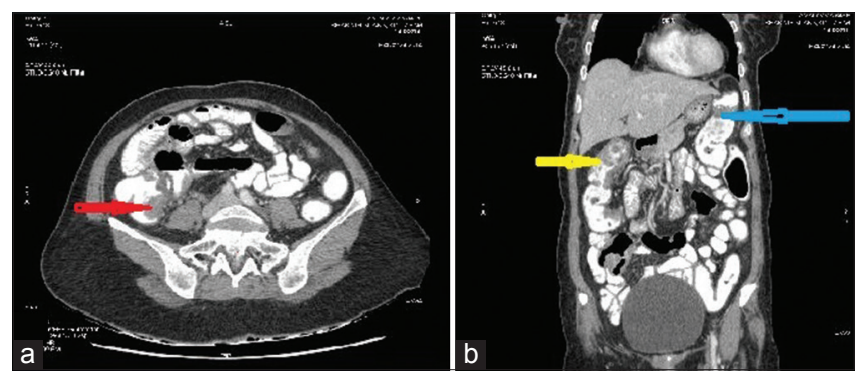

Figure 1: Computed tomography pictures showing multicentric stricturizing colonic lesions (a) transverse section showing mass involving cecum measuring $24 \mathrm{~mm} \times 25 \mathrm{~mm}$ (red arrow), (b) coronal section showing strictures in hepatic flexure of colon (yellow arrow), splenic flexure of colon (blue arrow)

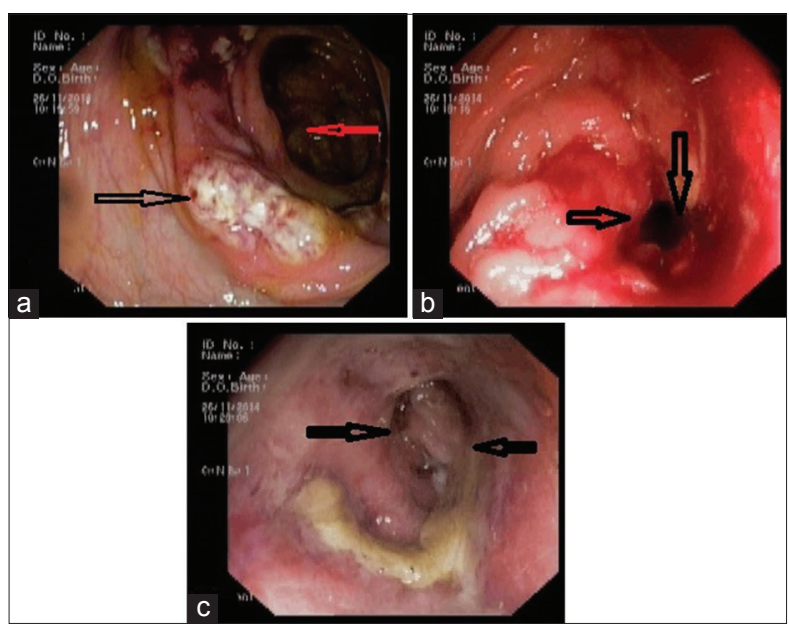

Figure 2: Colonoscopic pictures showing (a) cecal ameboma (black arrow), ileocecal valve (red arrow). Stricturizing ulcerated lesions in (b) proximal transverse colon (black arrows), (c) splenic flexure of colon (black arrows)

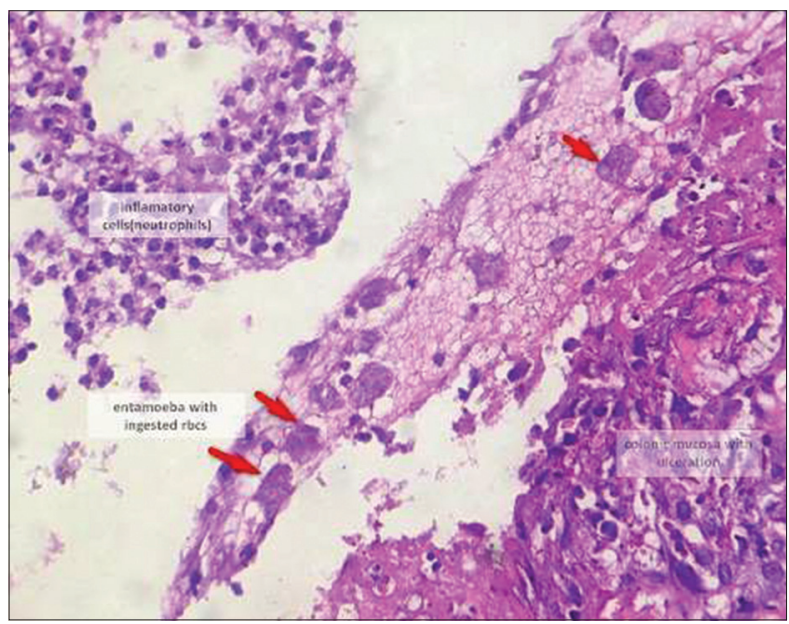

Figure 3: Microscopic picture of multicentric amebomashowing trophozoites with ingested RBCs( red arrows)

chronic colitis that can be asymptomatic which sometimes makes its appearance unforeseen. ${ }^{[9]}$ In decreasing order of frequency lesions develop in the caecum, appendix, and rectosigmoid region. Other sites include hepatic flexure, the transverse colon, and splenic flexure. ${ }^{[6]}$ Amebomas may 
cause obstructive symptoms. The differential diagnoses include Crohn's disease and appendiceal abscesses in younger individuals and colon cancer and diverticulitis in the elderly. ${ }^{[10,11]}$ Contrast-enhanced tomography and colonoscopy are sensitive tools for the work up of differential diagnosis of a cecal mass. ${ }^{[11]}$ Endoscopic evaluation yields a definitive diagnosis in about $60 \%$ of cases. Because ameboma is a rare condition, it is usually discovered at laparotomy. ${ }^{[12]}$ Only a few cases have been reported where the diagnosis was made by biopsy through a colonoscopy and successfully treated with pharmacotherapy. ${ }^{[13]}$

In our case, the patient presented with abdominal pain with associated weight loss, constipation, and vomiting. Clinical examination and imaging techniques were suggestive of colonic mass. Colonoscopic evaluation revealed multiple ulcerated stricturizing lesions in the colon, resembling gross features of Crohn's disease. Histopathological examination showed multicentric necrotic colonic mass with granulation tissue and trophozoites of E. histolytica. Thus, the diagnosis of ameboma was made and treatment started with ornidazole with complete resolution of symptoms. Our case report shows that ameboma can very rarely mimic Crohn's disease in its presentation as stricturizing multicentric granulomas. An accurate diagnosis of ameboma is critical because ameboma patients if treated for inflammatory bowel disease with glucocorticoids can develop fulminant colitis. Hence, having the differential diagnosis of ameboma in mind in patients with suspected Crohn's disease may be useful (especially in tropics) ${ }^{[6]}$ and the gold standard for the diagnosis of amoebic colitis remains colonoscopy and biopsy.

\section{Conclusion}

Ameboma, a granulomatous pseudotumor of colon is an uncommon complication of chronic asymptomatic amebic colitis. It can very rarely affect multiple parts of the colon other than caecum and produce stricturizing ulcerated lesions as in our case. Multicentric colonic amebomas can be misdiagnosed as Crohn's disease or colon cancer. A high index of suspicion is needed when dealing with colonic masses, especially in tropics and subtropics.

\section{Financial support and sponsorship}

Nil.

\section{Conflict of interest}

There are no conflict of interest.

\section{References}

1. Stanley SL Jr. Amoebiasis. Lancet 2003;361:1025-34.

2. Peláez M, Villazón A, Sieres Zaraboso R. Amebic perforation of the colon. Dis Colon Rectum 1966;9:356-62.

3. Li E, Stanley SL Jr. Protozoa. Amebiasis. Gastroenterol Clin North Am 1996;25:471-92.

4. Hardin RE, Ferzli GS, Zenilman ME, Gadangi PK, Bowne WB. Invasive amebiasis and ameboma formation presenting as a rectal mass: An uncommon case of malignant masquerade at a western medical center. World J Gastroenterol 2007;13:5659-61.

5. Misra SP, Misra V, Dwivedi M. Ileocecal masses in patients with amebic liver abscess: Etiology and management. World J Gastroenterol 2006;12:1933-6.

6. Fernandes H, D'Souza CR, Swethadri GK, Naik CN. Ameboma of the colon with amebic liver abscess mimicking metastatic colon cancer. Indian J Pathol Microbiol 2009;52:228-30.

7. Takahashi T, Gamboa-Dominguez A, Gomez-Mendez TJ, Remes JM, Rembis V, Martinez-Gonzalez D, et al. Fulminant amebic colitis: Analysis of 55 cases. Dis Colon Rectum 1997;40:1362-7.

8. Rashidul Haque, Christopher D.Huston, Molly Hughes, Eric Houpt, William A.Petri. Amoebiasis current concepts. N Engl J Med 2003;348:1565-73.

9. Bredin C, Margery J, Bordier L, Mayaudon H, Dupuy O, Vergeau B, et al. Diabetes and Amoebiasis: A high risk encounter. Diabetes Metab 2004;30:99-102.

10. Majeed SK, Ghazanfar A, Ashraf J. Caecal amoeboma simulating malignant neoplasia, ileocaecal tuberculosis and Crohn's disease. J Coll Physicians Surg Pak 2003;13:116-7.

11. Fenoglio-Preiser CM, Noffinsinger AE, Stemmerman GN, Lantz PE, Listrom MB, Rilke FO. Non neoplastic lesions of the colon. In: Gastrointestinal Pathology: An Atlas and Text. $2^{\text {nd }}$ ed. Philadelphia: Lippincott-Raven; 1999.

12. Ray G, Iqbal N. Right colonic mass with hepatic lesion - Remember ameboma? Indian J Gastroenterol 2006;25:272.

13. Sharma D, Patel LK, Vaidya VV . Amoeboma of ascending colon with multiple liver abscesses. J Assoc Physicians India 2001;49:579-80. 